\title{
Economía creativa y desarrollo urbano en España: una aproximación a sus lógicas espaciales
}

Ricardo Méndez. Centro de Ciencias Humanas y Sociales (CCHS) - Consejo Superior de Investigaciones Científicas (CSIC), Madrid, España.

Juan J. Michelini. Centro de Ciencias Humanas y Sociales (CCHS) - Consejo Superior de Investigaciones Científicas (CSIC), Madrid, España.

José Prada. Centro de Ciencias Humanas y Sociales (CCHS) - Consejo Superior de Investigaciones Científicas (CSIC), Madrid, España.

Jesús Tébar. Madrid, España.

RESUMEN | Durante la última década, la llamada economía creativa ha recibido creciente atención en los estudios sobre desarrollo urbano. El artículo propone, como punto de partida, un análisis crítico de algunos conceptos y perspectivas habituales, con el objetivo de precisar su significado actual y las diversas lógicas espaciales que presiden su distribución. Con esa base se analizan los sectores creativos en España, considerando tanto su peso en la economía urbana como la lógica espacial que determina su distribución territorial. El estudio se realiza a dos escalas espaciales: por un lado, se considera el sistema urbano en su conjunto, tomando como referencia las áreas urbanas definidas por el Ministerio de Fomento; y, por otro, se realiza un análisis comparativo a escala metropolitana entre Madrid y Barcelona. La combinación de ambas perspectivas permite matizar la habitual referencia a la concentración espacial de estas actividades y proponer futuras líneas de investigación.

PALABRAS CLAVE | competitividad urbana; desarrollo urbano; economía urbana y sociedad del conocimiento.

ABSTRACT | Over the last decade, creative industries have received increasing attention in urban development studies. As a starting point, the article proposes a critical analysis of some usual concepts and perspectives, to clarify the meaning of the creative economy in urban development. On this basis, we analyze the creative sectors in Spain, both from the point of view of their importance in urban economy and of the spatial logic that determines its territorial distribution. The study considers two spatial scales: one, it focuses on the urban system, with reference to the urban areas defined by the Ministry of Public Works and Transport (Ministerio de Fomento); and two, it carries out a comparative analysis, at a metropolitan level, between Madrid and Barcelona. The use of both perspectives allows us to offer a more nuanced vision of the habitual reference to the spatial concentration of these activities and propose new perspectives for future research.

KEY WORDS | urban competitiveness, urban development, urban economy, and knowledge society.

Recibido el 22 de febrero de 2011, aprobado el 5 de julio de 2011.

E-mail: Ricardo Méndez, ricardo.mendez@cchs.csic.es|Juan J. Michelini, juan.michelini@cchs.csic.es|José Prada, jose.prada@cchs.csic.es| Jesus Tebar, jesus.tebar@cchs.csic.es jesus.tebar@cchs.csic.es

El artículo forma parte de los proyectos financiados por el Plan Nacional de I+D+i español sobre "Las regiones metropolitanas españolas en la sociedad del conocimiento: tendencias económicas y transformaciones territoriales" (CSO2009-10888) y "Gobernanza local, innovación y desarrollo urbano en entornos metropolitanos" (CSO2010-19002). 


\section{Introducción}

Las áreas urbanas de la Unión Europea se enfrentan al reto de elevar su capacidad competitiva y su sostenibilidad para hacer frente a las consecuencias derivadas de la crisis económica y, a más largo plazo, del efecto combinado que suponen la globalización de los mercados y el proceso de integración regional. Cobra así creciente importancia la identificación de actividades estratégicas, resistentes a la deslocalización y adaptadas tanto a su trayectoria como a su stock de recursos específicos para lograr una mejor inserción en la llamada economía del conocimiento.

En ese contexto aumenta el interés que suscitan las actividades integradas en la denominada economía creativa, debido a una serie de factores que se refuerzan mutuamente. En primer lugar, una visión de la economía del conocimiento que se libera del sesgo tecnológico asociado a la idea de la sociedad de la información, para incluir las actividades asociadas a la cultura, de un alto contenido simbólico $\mathrm{y}$ donde los recursos intangibles son pieza esencial para generar valor añadido. $\mathrm{Al}$ mismo tiempo, numerosas ciudades europeas muestran una elevada oferta de capital humano, patrimonial e intelectual, esencial para promover este tipo de bienes y servicios, cuya demanda también aumenta. Eso puede suponer la generación de nuevo empleo y contribuir, de paso, a renovar la imagen urbana, razón por la que el sector creativo se incorpora de forma creciente a las políticas de promoción económica y a las estrategias de regeneración y revitalización.

No obstante el interés que despierta, el concepto de economía creativa ha sido bastante difuso desde su aparición y son aún escasas las investigaciones destinadas a valorar la verdadera importancia que ella tiene y las claves de su selectiva distribución entre los diferentes tipos de ciudades que conforman los sistemas urbanos nacionales, así como a profundizar en la interpretación teórica de su lógica espacial y los nuevos tipos de desigualdades a que da lugar. Esos son los objetivos centrales del presente artículo, que en sus dos primeros apartados pretende revisar de forma crítica las definiciones aparecidas en la bibliografía internacional y algunas claves que orientan su distribución territorial, para aportar luego una panorámica sobre la economía creativa en el conjunto de áreas urbanas españolas, lo que permite su contrastación con estudios similares realizados en otros países y puede servir de contexto en el cual situar las monografías de ámbito local o sectorial publicadas hasta el momento.

Con esta perspectiva, las preguntas de investigación a que se ha pretendido responder se orientan en cuatro direcciones complementarias: (i) Cómo valorar los criterios utilizados de forma habitual para definir y delimitar la economía creativa; (ii) Qué importancia alcanza la economía creativa en España y qué pautas de localización caracterizan las diferentes actividades que la integran; (iii) En qué medida contribuyen a transformar la estructura territorial de las grandes aglomeraciones, es decir, hasta qué punto actividades que utilizan en gran medida recursos intangibles tienden a dispersarse a falta de restricciones materiales, o bien favorecen nuevos desequilibrios; (iv) Qué capacidad efectiva pueden tener como motores de desarrollo y regeneración urbana. 
Para alcanzar esos objetivos se ha realizado un análisis de la base de datos disponible en la Tesorería General de la Seguridad Social sobre el volumen de empresas y afiliados en las diferentes actividades que comprende la economía creativa según la Clasificación Nacional de Actividades Económicas (CNAE-2009), con datos a 31 de diciembre de 2009 y con una desagregación de dos dígitos, que es la disponible a escala local. Con el objetivo de ofrecer una perspectiva multiescalar que permita ir más allá de la tendencia a la aglomeración metropolitana en que insiste toda la bibliografía disponible, aquí se han combinado diversas unidades de análisis. No obstante, se ha prestado especial atención a la distribución entre las 851 áreas urbanas identificadas en el Atlas Estadístico de las Áreas Urbanas de España, del Ministerio de Fomento, que es el primer intento de delimitación oficial a partir de criterios homogéneos, y que no había sido utilizado antes desde esta perspectiva. Como complemento, se ha realizado una aproximación a las áreas de Madrid y Barcelona para comprobar las diferencias entre ambas derivadas de su específica trayectoria evolutiva y contexto institucional, pero también las semejanzas en cuanto a pautas de localización entre las ciudades que las integran. El trabajo finaliza con unas breves conclusiones sobre la aportación realizada, apuntando la necesidad de cambiar la escala de análisis e incorporar técnicas cualitativas de investigación para aproximarse a las claves interpretativas que subyacen a algunas de las tendencias observadas.

\section{Significado de la economía creativa para el desarrollo urbano: principales argumentos y debates actuales}

La creciente importancia que en la última década se concede a la inserción de las ciudades y regiones europeas en una sociedad y economía del conocimiento ha difundido un discurso en el que conceptos como creatividad, aprendizaje o innovación se convierten en factores clave, no solo para elevar su competitividad, sino también para avanzar hacia mayores cotas de cohesión y sostenibilidad.

La creatividad, entendida como capacidad de aportar respuestas nuevas y más eficaces frente a los retos a que se enfrentan individuos, sociedades o territorios, se ha convertido en concepto de uso cada vez más frecuente en la bibliografía internacional de los últimos años. El interés que suscita la referencia a las industrias creativas, la clase creativa o la ciudad creativa ha multiplicado la bibliografía científica dedicada a estas cuestiones, pese a las frecuentes imprecisiones que acompañan la traslación del concepto al ámbito de los estudios sobre desarrollo territorial. También es destacable la importancia que le otorgan diversas instituciones internacionales (Unesco, 2006; Unctad, 2008, 2010; Comisión Europea, 2010), de lo que puede ser buen exponente la declaración, por parte de la Unión Europea, de 2009 como Año Europeo de la Creatividad y la Innovación.

En relación con la economía creativa y su impacto sobre el desarrollo urbano - que es la perspectiva desde la que aquí se aborda esa temática general-, la utilización originaria del concepto procede del Department of Culture, Media and 
Sports (DCMS) del Reino Unido, con la aprobación de una agenda de políticas públicas destinadas a su promoción. Se trató de un momento clave para la trayectoria posterior del debate académico y la reorientación de las políticas relativas a la cultura, en el que destaca la influencia del Creative Industries Mapping Document (DCMS, 1998) para la difusión del concepto a otros países. En este sentido, la traducción más aproximada al castellano del término creative industries sería el de sectores creativos, que responde mejor al amplio conjunto de actividades, no solo industriales, que representan estas ramas de actividad, pese a que en algunos documentos oficiales (Comisión Europea, 2010) este concepto se ha trasladado de forma literal al castellano como industrias creativas, más próximo a la raíz anglosajona.

Más allá de la difusión del concepto, sin embargo, la importancia relativa de las industrias creativas como generadoras de empleo es aún muy modesta. Los datos de Eurostat correspondientes a 2009 sitúan su presencia en torno al 4,4\% del empleo total dentro de la Unión Europea, lo que eleva su participación respecto a estudios anteriores con datos de mediados de la década (KEA, 2006; Power \& Nielsen, 2010). En ese contexto, España ocupa una posición intermedia, ligeramente por debajo del promedio (3,8\% del empleo total) y a mayor distancia de quienes ocupan las primeras posiciones (Finlandia: 6,2\%; Suecia: 5,9\%; Dinamarca: 5,7\%), en un nivel similar al de otros países mediterráneos y claramente por encima de los países orientales (Cuadro 1). No obstante, el valor estratégico que ahora se les atribuye en numerosos estudios y documentos oficiales considera sobre todo criterios de índole cualitativa que van más allá de esas simples cifras. Desde tal perspectiva, la construcción de una narrativa de la creatividad (O’Connor, 2008, p. 44) que, al igual que ocurre con otras metáforas, se ha difundido con cierta rapidez, desarrolló todo un conjunto de argumentos que pretenden justificar el valor estratégico actual de las industrias y servicios creativos para el desarrollo territorial y la necesidad de acciones destinadas a su promoción.

En primer lugar, se trata de actividades intensivas en el uso del conocimiento y con una demanda creciente a escala internacional, lo que parece asegurar su capacidad para generar empleo y valor añadido en el próximo futuro, junto con su efecto multiplicador sobre otras actividades. Así, la progresiva mercantilización de la cultura, que sitúa en el mercado una importante oferta de bienes con alto contenido simbólico, y las políticas públicas que prestan creciente atención al patrimonio y a determinados hitos culturales, se suman en la misma dirección y buena parte de los países europeos parecen contar con un elevado stock de este tipo de capital (Manito, 2010).

Una parte significativa de esos puestos de trabajo exige recursos humanos con elevado nivel formativo, y por ello suelen asociarse con empleos de cierta calidad y estabilidad. Ya en 1962, la referencia pionera de Machlup a la economía del conocimiento consideró que entre los grupos profesionales en expansión dentro de las economías avanzadas estaban los relacionados con la creación artística, los medios de comunicación y los servicios de información, vinculación que se se ha visto reforzada en las recientes aproximaciones a los denominados trabajadores del conocimiento (Stehr, 2002) o la clase creativa (Florida, 2002). 
CUADRO 1 | Distribución del empleo en economía creativa en la Unión Europea, 2009

\begin{tabular}{|c|c|c|c|c|c|}
\hline PaÍs & $\begin{array}{l}\text { MILES DE } \\
\text { EMPLEOS }\end{array}$ & $\begin{array}{c}\text { \% EMPLEO } \\
\text { TOTAL }\end{array}$ & PaÍS & $\begin{array}{l}\text { MILES DE } \\
\text { EMPLEOS }\end{array}$ & \% EMPLEO TOTAL \\
\hline Alemania & $1.929,6$ & 5,0 & Irlanda & 100,1 & 5,2 \\
\hline Austria & 196,7 & 4,8 & Italia & $1.055,7$ & 4,6 \\
\hline Bélgica & 168,5 & 3,8 & Letonia & 40,1 & 4,1 \\
\hline Bulgaria & 92,8 & 2,9 & Lituania & 44,0 & 3,1 \\
\hline Chipre & 11,9 & 3,1 & Luxemburgo & 4,6 & 2,1 \\
\hline Dinamarca & 157,5 & 5,7 & Malta & 1,5 & 0,9 \\
\hline Eslovaquia & 69,3 & 2,9 & Países Bajos & 441,8 & 5,1 \\
\hline Eslovenia & 45,8 & 4,7 & Polonia & 544,9 & 3,4 \\
\hline España & 725,9 & 3,8 & Portugal & 122,8 & 2,4 \\
\hline Estonia & 5,9 & 1,0 & Reino Unido & $1.622,9$ & 5,6 \\
\hline Finlandia & 153,3 & 6,2 & República Checa & 205,7 & 4,2 \\
\hline Francia & $1.081,0$ & 4,2 & Rumania & 134,3 & 1,5 \\
\hline Grecia & 191,3 & 4,2 & Suecia & 265,9 & 5,9 \\
\hline Hungría & 141,5 & 3,7 & $\begin{array}{l}\text { Unión } \\
\text { Europea-27 }\end{array}$ & $9.626,3$ & 4,4 \\
\hline
\end{tabular}

FUENTE EURostat, 2010.

Los recursos que utilizan los sectores creativos, a menudo intangibles, se concentran sobre todo en determinadas ciudades y tienen un carácter específico en tanto que construcción social, lo que limita el riesgo de deslocalización empresarial en busca de áreas con menores costos respecto de otro tipo de actividades más móviles. Al mismo tiempo, las diferencias en los recursos heredados, pero también la diversa capacidad de las sociedades locales para ponerlos en valor o generar otros nuevos, se convierte en factor de nuevas desigualdades interurbanas. Por todo ello, las industrias y servicios creativos son objeto de creciente atención por parte de las políticas urbanas, por su efecto potencial tanto en la revitalización económica como en la construcción de nuevas imágenes y en la renovación de determinadas áreas mediante el planeamiento (Mommaas, 2004).

En resumen, frente a la necesidad actual de recuperar un crecimiento consistente y a largo plazo, basado en ventajas competitivas dinámicas, "las industrias culturales y creativas representan un conjunto de empresas altamente innovadoras, con un gran potencial económico, y constituyen uno de los sectores más dinámicos en Europa" (Comisión Europea, 2010, p. 2). Pero más allá del indudable interés por el concepto, resulta paradójico constatar cierto clima de confusión como consecuencia de la persistente indefinición sobre aspectos clave del debate en torno a 
las actividades creativas y su papel en el desarrollo territorial. El aspecto más problemático y de mayor calado tiene que ver con su propia definición, que la propia Unctad (2008) reconoce como cuestión de considerable inconsistencia y frecuente desacuerdo, al tratarse de un concepto subjetivo, en evolución y a menudo autorreferente, que no admite una única forma de aproximación sino "maneras diferentes de interpretar las características estructurales de la producción creativa” (p. 8).

Según Throsby (2008, p. 1), esa indefinición se relaciona con la amplitud de la propuesta inicial de la DCMS, que definió estas actividades como "aquellas que requieren creatividad, cualificación y talento, con potencial para la generación de riqueza y empleo mediante la explotación de los derechos de propiedad intelectual", lo que derivó en muy diversas interpretaciones según instituciones y países. Para Cooke y Lazzeretti (2008), uno de los aspectos más críticos deriva de la utilización a menudo indistinta de los conceptos de economía cultural y economía creativa, pues ambas guardan estrecha relación en la medida en que enfatizan tanto el papel del capital humano y las redes sociales como la creatividad de profesiones específicas, pero subrayan sus "diferentes modos de producción, bases institucionales y contenido estético" (p. 1). Así, mientras una parte de las industrias y servicios culturales genera bienes públicos ofertados por el Estado, las creativas integran una gama muy amplia de actividades cuya demanda está orientada fundamentalmente por el mercado y movida por la competencia entre actores económicos.

Aunque no es este el lugar para profundizar en ese debate (Garnham, 2005; O'Connor, 2008), cabe señalar que una consecuencia negativa de esa indefinición desde la perspectiva de los estudios sobre desarrollo es la falta de acuerdo en relación con las actividades que deben incluirse dentro de la economía creativa. Se trata de una cuestión clave que afecta la forma en que "se evalúa el tamaño, naturaleza y perspectivas de las industrias analizadas, así como el tipo de políticas y programas más apropiados para desarrollarlas" (Cunningham, 2002, p. 2). Esa ambigüedad conceptual, junto con los cambios producidos en las clasificaciones internacionales y nacionales de actividades o la desigual disponibilidad de datos estadísticos según países, momentos y escalas espaciales de análisis, tiene su reflejo en una notable heterogeneidad entre los estudios dedicados a su análisis en función de las actividades incluidas o excluidas en cada caso, heterogeneidad que impide la comparación y de la cual pueden ser exponente informes muy citados para Europa, como los de KEA European Affairs y European Cluster Observatory.

En ese contexto, es importante destacar el esfuerzo desarrollado por la Organización de las Naciones Unidas para impulsar el propio concepto y unificar criterios en su definición y delimitación, y en la creación de bases estadísticas de ámbito internacional. Por ello, los Creative Industries Reports (Unctad, 2008 y 2010) se han convertido en referencia frecuente, tanto en su definición de la economía creativa como aquella "basada en la producción de bienes simbólicos, dependientes de derechos de propiedad y dirigidos a un mercado lo más amplio posible" (Unctad, 2008 , p. 13), como en la delimitación de actividades que se incluyen, muy próxima a la propuesta por la Comisión Europea (2010) y utilizada también en nuestro caso como base para el análisis realizado. 
Siguiendo la idea de actividades centrales y periféricas adoptada por otras clasificaciones, la ONU plantea una distinción inicial entre upstream activities - actividades artísticas de diversa índole o relacionadas con el patrimonio culturaly downstream activities - publicidad, diseño, edición, productos audiovisuales y multimedia, junto con otras actividades relacionadas-. Con esa base, divide los sectores culturales y creativos en cuatro grupos. El primero de ellos, definido como Heritage, que se identifica como el alma de ese conjunto, muy vinculado a la existencia de recursos patrimoniales, engloba los espacios culturales (bibliotecas, museos, archivos, etcétera) y las actividades culturales tradicionales (artesanía, tradiciones, festivales, etcétera). Un segundo grupo, definido como Arts, abarca sectores relacionados con el mundo del arte, las actividades artísticas y de espectáculos. Una tercera categoría, Media, desarrolla productos creativos dirigidos a un público amplio, ya sean publicaciones (libros, revistas, entre otros) o productos audiovisuales (cine, televisión, radio, música, etcétera). Finalmente, las Functional Creations incluyen aquellos sectores más vinculados a demandas del mercado, como el diseño, software (videojuegos, contenidos digitales, otros), o servicios con alto contenido creativo (arquitectura, publicidad, etcétera).

Tomando como referencia esa propuesta, en su aplicación al sistema urbano español se ha considerado un total de nueve grupos de actividad, correspondientes a la Clasificación Nacional de Actividades Económicas (CNAE) de 2009, con una desagregación a dos dígitos, que es la disponible para estudios a escala local. Aunque la traslación de esa clasificación no es exacta y supone cierta sobrevaloración en el caso de los servicios pertenecientes al último grupo, al incluir también actividades como la ingeniería o las empresas que realizan estudios de mercado, sí permite diferenciar con claridad los distintos grupos de actividades (Figura 1). Están, en primer lugar, las actividades que guardan mayor relación con diferentes formas de creación artística o con el patrimonio cultural (grupos 90 y 91). Están, luego, las empresas tradicionalmente identificadas con las industrias culturales, que comprenden la edición e impresión, las industrias y servicios audiovisuales, edición de programas informáticos y videojuegos (grupos 18, 58, 59 y 60), que permiten un análisis más pormenorizado. Están, finalmente, los considerados como servicios creativos en ámbitos como la arquitectura e ingeniería (grupo 71), publicidad y estudios de mercado (grupo 73), y otros servicios profesionales como diseño, fotografía o traducción (grupo 74).

En resumen, podría decirse que la economía creativa plantea ciertas insuficiencias conceptuales de origen, pues la asociación de la noción de creatividad con unas determinadas actividades supone una visión sesgada de la realidad. Plantea también debates metodológicos relativos a su delimitación, pues excluir, por ejemplo, a las instituciones de $\mathrm{I}+\mathrm{D}+\mathrm{i}$ - Investigación, Desarrollo e innovación- e incluir las artes gráficas entre los sectores altamente creativos solo es explicable por la genealogía de un concepto derivado en sus orígenes del más consolidado de economía cultural. Conlleva, por último, dificultades de traslación derivadas de la clasificación oficial de actividades - que en España, por ejemplo, no permite aislar un sector de moda 
para diferenciarlo de las restantes industrias de confección o calzado- y del escaso nivel de desagregación de la información disponible a escala local. Pero, pese a ello, parece útil ofrecer una panorámica de conjunto sobre sus lógicas espaciales en el interior del sistema urbano y revisar, con esa perspectiva, algunas de las ideas difundidas en la bibliografía internacional de los últimos años.

FIGURA I Identificación de las actividades integradas en la economía creativa en España según criterio Unctad y clasificación CNAE-2009

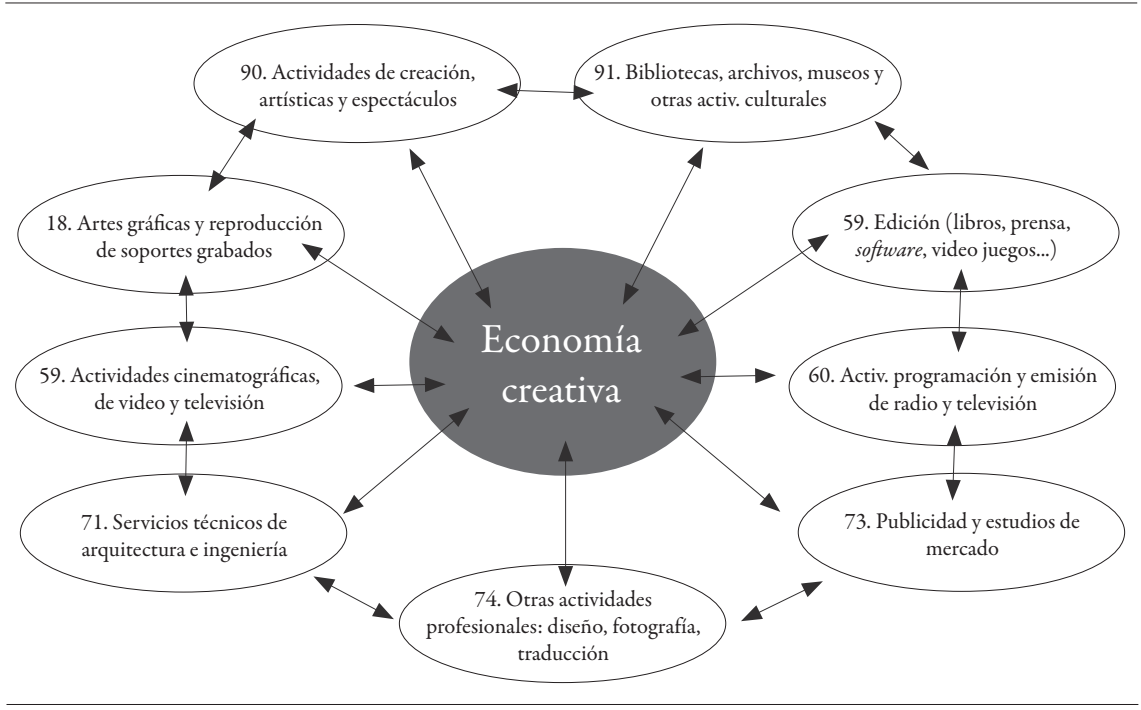

FUENTE Elaboración PROPIA, ADAPTAdo DE UNCTAD, 2008.

\section{Las lógicas espaciales de la economía creativa}

Pese a la creciente atención prestada a la economía creativa en los últimos años, las investigaciones que analizan sus pautas de distribución en las regiones o los sistemas urbanos son bastante menos numerosas que las monografías de ámbito local o sectorial. En el caso de la Unión Europea, son mayoría las realizadas en el Reino Unido a partir de los informes iniciales del Department of Culture, Media and Sports, continuados en publicaciones más recientes (Higgs, Cunningham \& Bakhsi, 2008; De Propris, Chapain, Cooke, MacNeill \& Mateos-García, 2009). Entre los intentos para ofrecer una panorámica a escala supraestatal pueden mencionarse el de Lazzeretti, Boix y Capone (2008), que comparó la distribución de las actividades creativas entre los mercados locales de empleo de Italia y España, ampliado posteriormente para integrar también los de Francia y el Reino Unido (Boix, Lazzeretti, Capone, De Propris \& Sánchez, 2010), mientras el de Kovács, Murie, Musterd, Gritsai y Pethe (2007), realizado en el marco del proyecto ACRE, contrasta la 
situación y dinámicas en trece metrópolis europeas, y el de Power y Nielsen (2010) lo hace para el conjunto de las regiones de la UE, tomando como base las NUTS-2 (Nomenclatura de las Unidades Territoriales Estadísticas-2).

Para España solo se cuenta por el momento con los dos trabajos mencionados, que utilizan como fuente el censo de población de $2001 \mathrm{y}$, como unidades territoriales, los 806 mercados locales de trabajo delimitados para un estudio previo sobre distritos industriales (Boix \& Galetto, 2006), lo que ofrece resultados bastante detallados y permite asimilarlos al concepto de sistemas creativos locales propuesto por Capone (2008). Una aproximación complementaria a la economía del conocimiento en el sistema urbano español es la de Méndez y Sánchez Moral (2011), que analizan la distribución de las actividades culturales y creativas junto con el capital humano, la inversión y resultados de la innovación o la dotación de infraestructuras digitales para todas las ciudades por encima de 20.000 habitantes. En una perspectiva diferente se cuenta con el estudio de Pesquera, Casares, Coto Millán e Inglada (2010), que aborda la distribución territorial de la supuesta clase creativa identificada por Florida $(2002,2005)$ y su asociación espacial con indicadores más o menos discutibles de tecnología-talento-tolerancia a diferentes escalas, incluida la urbana.

A partir de la investigación disponible, tres son los argumentos más reiterados sobre las tendencias dominantes en la distribución espacial de los sectores creativos: (i) su fuerte tendencia a la concentración, visible a diferentes escalas; (ii) su propensión a promover la formación de clusters localizados; y (iii) la existencia de trayectorias locales específicas, ligadas a las herencias de cada ciudad. Tales argumentos constituyen hipótesis que pueden ser contrastadas, y discutidas a partir del análisis aquí realizado.

Procesos de concentración metropolitana. El primer rasgo que define el comportamiento espacial de empresas e instituciones ligadas a la economía creativa es, sin duda, su tendencia a la aglomeración en un número limitado de lugares. A escala del sistema urbano, se constata en todos los casos una neta primacía de las mayores regiones metropolitanas; en su interior, las grandes ciudades suelen ejercer un similar efecto de polarización al actuar como creative hubs, lo que limita su contribución al desarrollo de estructuras policéntricas; finalmente, dentro de estas resulta frecuente su agrupamiento en determinados barrios o áreas, donde sirve incluso como elemento de impulso en algunas políticas de regeneración.

A esta evidencia habitual puede añadirse la precisión aportada por Scott y Leriche (2005, p. 210) para las industrias y servicios culturales, pero aplicable al conjunto de la economía creativa. Estos autores destacan la mayor concentración de las actividades que producen bienes móviles, debido a las ventajas competitivas de agruparse, frente a aquellas otras asociadas a bienes inmóviles de carácter patrimonial cuya distribución se relaciona con herencias locales específicas, por lo que pueden resultar más dispersas. Otros aspectos, como la estructura empresarial, el tipo y volumen de insumos materiales utilizados, sus exigencias de cualificación laboral, el carácter privado o pú- 
blico de su gestión, etcétera, también suponen diferentes lógicas espaciales y grados de concentración a distintas escalas. La consecuencia es que las actividades creativas, así como los trabajadores altamente cualificados que trabajan en ellas, tienen una importancia creciente en la nueva jerarquía metropolitana. Según Scott (2009), "proporciones significativas del empleo total en las mayores áreas metropolitanas se concentran en servicios de alto nivel y actividades culturales; en las pequeñas áreas urbanas, por el contrario, la mayor parte de los perfiles profesionales siguen estando dominados por las actividades industriales y similares", si bien "esas pequeñas áreas urbanas también muestran una enorme variedad de formas individuales de especialización económica" (p. 207). Resulta, en cambio, bastante menos conocida la relevancia alcanzada por ciertas ciudades medias en determinadas regiones, generalmente monoespecializadas en una determinada rama de actividad. Si bien se cuenta con algunas monografías, se ha profundizado menos hasta el momento en la identificación de posibles ventajas comparativas genéricas o en la capacidad dinamizadora del milieu local en tanto que formación socioeconómica territorializada y activa, en la línea propuesta por Törnqvist (1983) para lo que denominó ambiente creativo.

Las explicaciones convencionales sobre la concentración metropolitana del empleo en estas actividades, bastante superior a la que representan en el conjunto de la economía, han destacado, sobre todo, la importancia de los calificados como hard location factors (Musterd, Bontje, Chapain, Kovács \& Murie, 2007). Señalan así las externalidades positivas derivadas de la presencia de recursos tangibles, como infraestructuras, equipamientos y servicios de calidad, una oferta inmobiliaria amplia, la presencia de instituciones universitarias y de $\mathrm{I}+\mathrm{D}$, o la disponibilidad de abundante capital humano, así como un mercado de trabajo cualificado y diversificado.

Pero en los últimos años la atención se ha desplazado hacia los soft location factors, de carácter más intangible, a partir de la ya mencionada propuesta de Florida sobre la clase creativa y las razones que pueden atraer su ubicación en determinadas ciudades. Tanto las numerosas investigaciones dedicadas a verificar sus hipótesis (Gertler, Florida, Gates \& Vinodrai, 2002; Stolarick \& Florida, 2006; Florida, Mellander \& Stolarick, 2008...), como aquellas otras que revisan de forma crítica sus argumentos (Glaeser, 2004; Peck, 2005; Shearmur, 2006...), han contribuido a abrir el debate sobre la influencia que la calidad de vida urbana, asociada a conceptos como diversidad sociocultural, tolerancia, amenidades, etcétera, puede tener sobre la atracción de talentos y la concentración de empresas creativas, sin aportar resultados demasiado concluyentes.

En definitiva, esta atención a los soft factors se justifica por la creciente desmaterialización de economías metropolitanas donde los flujos de información, conocimiento y capital son los que movilizan una proporción creciente de sus actividades y trabajadores. Pero son sin duda los network location factors, que destacan las relaciones que se tejen entre las empresas y los restantes actores locales, o la densidad institucional (institutional thickness) señalada por De Propris et al. (2009: 12), los argumentos que han suscitado mayor atención por su influencia directa sobre la aparición de ventajas competitivas y la consolidación de clusters creativos localizados. 
De la formación de clusters a la diversidad de trayectorias urbanas. La tendencia mostrada por numerosos sectores creativos a agruparse en determinadas localizaciones ha favorecido la traslación del concepto de cluster a buena parte de la bibliografía disponible. Puede considerarse como precedente la idea de distrito cultural surgida en Italia (Santagata, 2005; Lazzeretti, 2006), que traslada al análisis de estos sectores el concepto marshalliano de distrito industrial. A partir de actividades o eventos culturales muy diversos, identificaron las relaciones entre empresas industriales, comerciales, de servicios o turísticas derivadas, así como las redes de actores institucionales (gobiernos, universidades, centros tecnológicos, organizaciones sociales), patrocinadores (bancos, fundaciones) y artistas o artesanos, que sustentan una estructura interna compleja y dinámica.

El concepto más difundido hoy es el de cluster creativo, que suele entenderse como una aglomeración de empresas pertenecientes a una misma rama de actividad creativa en un determinado lugar, que compiten y cooperan manteniendo entre sí relaciones de mercado o al margen del mismo, así como con otras entidades locales. Se generan con ello ventajas competitivas derivadas de las dinámicas de proximidad entre trabajadores creativos que favorecen el intercambio de conocimiento tácito, así como de la existencia de instituciones y convenciones específicas, favorables al fomento de la propia creatividad y base de las denominadas ciudades creativas (Scott, 2006). Junto con las economías de localización, más relacionadas con la complementariedad entre empresas del mismo sector o que trabajan en torno a determinados productos, las grandes regiones metropolitanas añaden las economías de urbanización ligadas a la diversidad de actividades y cualificaciones en el mercado de trabajo, así como al buzz local (Storper \& Venables, 2004), concepto que pretende referirse a la alta densidad de interacciones e intercambio de todo tipo de información entre diferentes actores locales, que generan un entorno difícil de reproducir en otros ámbitos.

La referencia al cluster creativo no queda, sin embargo, al margen de las críticas realizadas al concepto originario desde diversas perspectivas. Están, por un lado, los que señalan su uso a muy diferentes escalas espaciales y para concentraciones empresariales donde no siempre se acredita la existencia de interrelaciones, que pueden constituir verdaderos sistemas productivos integrados o simples agregados, según los casos (Martin \& Sunley, 2003). Por otra parte, todo cluster local está ligado a redes multiescalares que desbordan la propia ciudad y la relacionan de forma cada vez más intensa a clientes, proveedores, mercados y fuentes externas de capital o conocimiento, lo que resulta de especial importancia en el caso de esta economía creativa, aunque no siempre se le dedica la atención suficiente (Bathelt, Malmberg \& Maskell, 2004; Fernández \& Brandão, 2010; Vale, 2011).

Por último, asociado a la importancia del lugar, sus recursos y actores, o a las características socioculturales e institucionales heredadas, se ha difundido el concepto de path dependence, que destaca la existencia de trayectorias específicas en la evolución de las economías urbanas que solo pueden ser plenamente comprendidas a partir de la historia local (Simmie, Carpenter, Chadwick \& Martin, 2008). Como 
señalan Musterd et al. (2007: 15), "la path dependence explica en gran medida el diferente potencial de ciudades y regiones" para desarrollar una economía creativa. Pero también ayuda a explicar la persistencia de determinadas especializaciones a lo largo del tiempo que, según Pierson (2000), favorecen la aparición de rendimientos crecientes derivados de las redes de interrelaciones formales e informales existentes, lo que retroalimenta determinados clusters vinculados a un saber hacer y a instituciones específicas.

Trasladado al ámbito aquí analizado, el concepto de path dependence puede explicar el diverso perfil de las áreas urbanas en cuanto a presencia de las diferentes actividades creativas en función de su particular evolución y del patrimonio material e inmaterial disponible. También es útil para interpretar las diferentes pautas de localización en el interior de las regiones metropolitanas, que cambian de forma lenta y se relacionan con la peculiar estructura urbana heredada, debido a la importante función de las inercias espaciales en esos procesos (Hall, 2004). Sin embargo, al considerar la influencia de las condiciones internas cobra especial significado la diversa capacidad mostrada por los actores locales para generar formas de gobernanza que favorezcan la elaboración de diagnósticos y planes estratégicos concertados, en los cuales se incluya la identificación y puesta en valor de los recursos locales en conocimiento, cultura y creatividad (Musterd \& Murie, 2010). Las ciudades que han construido coaliciones de actores favorables a este tipo de iniciativas, con su reflejo en políticas de promoción y ordenación activas en esta materia, también deberían resultar visibles en cualquier mapa de la economía creativa como el aquí planteado.

A partir de este conjunto de referencias teóricas, que pretenden sintetizar aquellos aspectos de la bibliografía internacional útiles para el estudio de la economía creativa en las áreas urbanas españolas, pueden señalarse las posibles aportaciones del artículo.

En primer lugar, las industrias y servicios culturales y creativos alcanzan una significativa importancia en las principales regiones metropolitanas; en concreto, las de Madrid y Barcelona ocupan destacadas posiciones en el ámbito europeo, pero apenas existen estudios sobre estas actividades para el conjunto del sistema urbano español. Al respecto, la inclusión de las 851 áreas urbanas definidas hace unos años por el Ministerio de la Vivienda puede permitir superar la habitual referencia a la concentración metropolitana para medir de manera precisa el peso relativo de algunas ciudades de tamaño medio que, bien por contar con un importante patrimonio cultural o por haber aplicado políticas de impulso a determinados clusters creativos, siguen trayectorias dignas de atención. Por otra parte, la comparación realizada entre las aglomeraciones de Madrid y Barcelona posibilita profundizar en las pautas de localización intrametropolitana de las diferentes actividades, a semejanza de lo realizado por Currid y Williams (2006) para Nueva York y Los Ángeles, y también distinguir entre características comunes y específicas, vinculadas a factores como la historia, el contexto institucional o las políticas aplicadas en cada caso, aspectos que tan solo quedan apuntados en el artículo. 


\section{La economía creativa en España: una concentración de carácter multiescalar}

Según la delimitación propuesta por la Unctad (2008), la economía creativa en España integra 64.484 empresas $(3,70 \%$ del total) y genera 706.871 empleos $(4,06 \%$ del total) al finalizar el año 2009 (Cuadro 2). En términos comparativos, esa cifra resulta similar, por ejemplo, a la del sector educativo (742.867 empleos), pero no llega a representar ni la mitad de las ocupaciones en el sector de la construcción (1,56 millones), uno de los responsables del modelo de crecimiento que entró en crisis en 2008. En términos cuantitativos su importancia relativa es, pues, modesta, pese al significado que hoy se le atribuye para potenciar el desarrollo urbano, bastante superior al que representan estas cifras.

Los servicios de publicidad y estudios de mercado, o de arquitectura, que en otro tipo de clasificaciones se integran dentro de los servicios avanzados a las empresas (knowledge intensive business services) son, con 341.063 trabajadores, la principal actividad en términos de empleo generado. Su contrapunto, en cambio, son aquellas otras que constituyen el núcleo central del sector cultural (actividades artísticas, de creación y espectáculos; bibliotecas, archivos y museos), que apenas suman 66.292 empleos, si bien en este caso las cifras oficiales pueden infravalorar la realidad ante la abundancia de microempresas y trabajadores autónomos en situación laboral cambiante, no siempre bien registrada.

CUADRO 2 | Importancia y estructura interna de la economía creativa en España, 2009

\begin{tabular}{|c|c|c|c|c|c|}
\hline ACTIVIDADES & $\begin{array}{l}\text { NÚMERO DE } \\
\text { AFILIADOS }\end{array}$ & $\%$ TOTAL & $\begin{array}{l}\text { NÚMERO DE } \\
\text { EMPRESAS }\end{array}$ & $\%$ TOTAL & $\begin{array}{c}\text { AFILIADOS/ } \\
\text { EMPRESA }\end{array}$ \\
\hline $\begin{array}{l}\text { Artes gráficas y reproducción de } \\
\text { soportes grabados }\end{array}$ & 85.623 & 0,49 & 9.420 & 0,54 & 9,09 \\
\hline Industria editorial & 75.591 & 0,43 & 4.923 & 0,28 & 15,35 \\
\hline $\begin{array}{l}\text { Actividades de cine, televisión, } \\
\text { sonido y edición musical }\end{array}$ & 39.632 & 0,23 & 3.129 & 0,18 & 12,67 \\
\hline $\begin{array}{l}\text { Actividades de programación y } \\
\text { emisión de radio/televisión }\end{array}$ & 26.885 & 0,15 & 1.325 & 0,08 & 20,29 \\
\hline $\begin{array}{l}\text { Servicios técnicos de arquitectura e } \\
\text { ingeniería }\end{array}$ & 231.134 & 1,33 & 23.308 & 1,34 & 9,92 \\
\hline Publicidad y estudios de mercado & 109.929 & 0,63 & 10.960 & 0,63 & 10,03 \\
\hline $\begin{array}{l}\text { Otras actividades profesionales, } \\
\text { científicas y técnicas }\end{array}$ & 71.785 & 0,41 & 6.112 & 0,35 & 11,74 \\
\hline $\begin{array}{l}\text { Actividades de creación, artísticas y } \\
\text { espectáculos }\end{array}$ & 50.508 & 0,29 & 3.795 & 0,22 & 13,31 \\
\hline $\begin{array}{l}\text { Bibliotecas, archivos, museos y otras } \\
\text { actividades culturales }\end{array}$ & 15.784 & 0,09 & 1.512 & 0,09 & 10,44 \\
\hline Economía Creativa & 706.871 & 4,06 & 64.484 & 3,70 & 10,96 \\
\hline Total Economía & 17.413 .913 & 100 & 1.744 .796 & 100 & 9,98 \\
\hline
\end{tabular}

Fuente Tesorería General de la Seguridad Social y elaboración propia. 
La repetida tendencia de los sectores creativos a la concentración territorial se pone de manifiesto a diferentes escalas y mediante el uso de diversas unidades espaciales de análisis, que ofrecen imágenes complementarias de una misma lógica predominante. Así ocurre al analizar su distribución a escala provincial, pues Madrid y Barcelona, con 209.989 y 132.045 empleos respectivamente, representan el $47,22 \%$ del total frente a algo menos del $30 \%$, si se considera su peso relativo en el empleo contabilizado en España en 2009 (Figura 2). Esa proporción asciende hasta el $57,69 \%$ si se añaden las provincias de Valencia, Sevilla y Vizcaya, que cuentan también con grandes aglomeraciones metropolitanas (41,56\% del empleo total). En el extremo opuesto, las 28 provincias que no llegan a representar ni un $1 \%$ del empleo español en economía creativa apenas suponen en conjunto un 12,31\% del volumen de ocupados en este tipo de actividades, poco más de la mitad de lo que representa su peso relativo en los efectivos laborales del país (23,04\%). Este contraste reproduce y acentúa el correspondiente a su diverso potencial económico, con valores más elevados de ocupación en los ejes Atlántico, Mediterráneo y del Ebro, además de Madrid y alguna otra capital regional interior (Sevilla, Valladolid). Más significativa resulta su especialización, calculada mediante cocientes de localización que miden su importancia relativa en cada provincia respecto al promedio español. En este caso son únicamente seis las provincias que superan el valor de la unidad, con Madrid y Barcelona también por encima del resto, mientras A Coruña y Valladolid superan en este caso a Valencia, en tanto solo Sevilla muestra cierta especialización entre las provincias del sur peninsular.

Pero la economía creativa es, por definición, patrimonio urbano. En una sociedad altamente urbanizada como la española, donde tres cuartas partes de su empleo se localizan ya en las 851 áreas urbanas con más de 5.000 habitantes (74,55\%), esa participación resulta aún mucho mayor en el caso de las industrias creativas, que concentran en ellas un $89,63 \%$ de los ocupados y alcanzan valores próximos al $95 \%$ en los casos de la edición, las actividades de radio y televisión, o la publicidad y estudios de mercado (Cuadro 3 y Figura 3). Tan solo en una actividad bastante relacionada con la provisión de equipamientos culturales por parte del sector público como es la de bibliotecas, archivos y museos, las áreas rurales se aproximan a una quinta parte $(19,31 \%)$ del empleo total, alcanzando también un 15,83\% en el caso de la industria de artes gráficas, que ha deslocalizado parte de su actividad hacia áreas de menores costos, pero bien comunicadas con sus principales mercados de consumo.

Las áreas urbanas de Madrid y Barcelona, con el 29,29\% y 17,91\% del empleo, respectivamente, se sitúan de nuevo a notable distancia del resto, pues la de Valencia, que les sigue en importancia, apenas representa el 3,84\% del total; entre las tres aglomeraciones suman más de la mitad del empleo creativo en España, por algo menos de un tercio del empleo total. Una vez más, la industria editorial demuestra una especial propensión a concentrarse en las dos mayores regiones metropolitanas del país, que suman seis de cada diez afiliados (59,35\% del total); algo parecido puede decirse de las empresas de publicidad, que reúnen en ellas al 55,98\% de sus empleados. La capacidad de atracción ejercida por las economías de localización y urbanización asociadas a la aglomeración espacial solo parece atenuarse en algunos servicios culturales que, en tanto que bienes públicos de manera mayoritaria, responden a lógicas de implantación algo diferentes, relacionadas con iniciativas 
de dinamización cultural y puesta en valor de su patrimonio emprendidas por gobiernos autonómicos y locales, si bien con incidencia desigual. Es lo que ocurre con las actividades de creación, artísticas y de espectáculos ( $45,71 \%$ de su empleo en Madrid y Barcelona), o las de bibliotecas, archivos y museos (38,74\%), si bien en cualquier caso su hegemonía es por el momento incontestada.

FIGURA 2 | Concentración y especialización de las provincias españolas en economía creativa, 2009
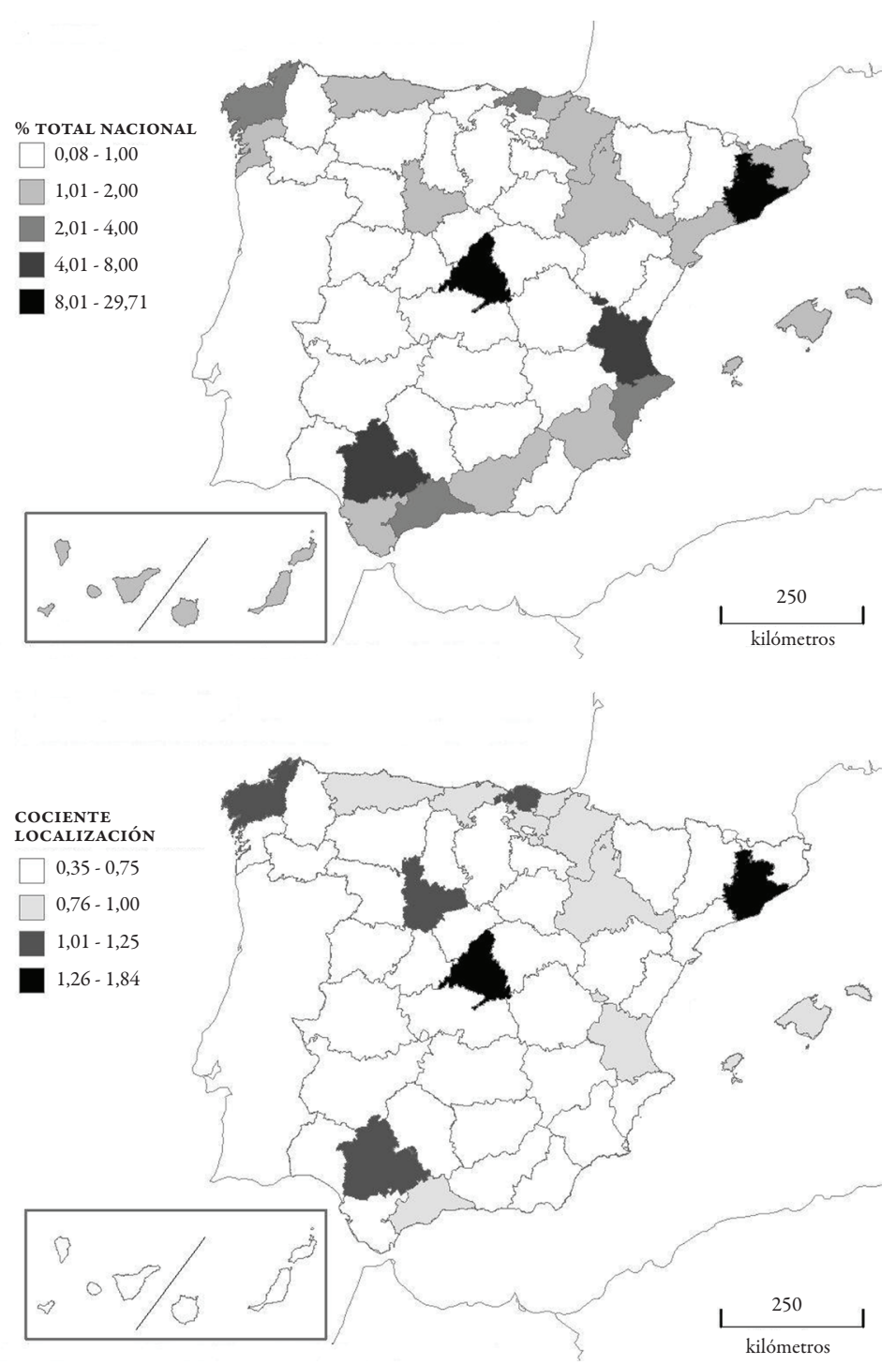

Fuente Tesorería General de la Seguridad Social y elaboración propia. 
CUADRO 3 | Concentración urbana del empleo en la economía creativa, 2009

\begin{tabular}{|c|c|c|c|c|c|c|c|c|}
\hline $\begin{array}{l}\text { ACTIVIDADES } \\
\text { ECONOMÍA } \\
\text { CREATIVA }\end{array}$ & $\begin{array}{c}\text { ÁREA } \\
\text { URBANA } \\
\text { MADRID }\end{array}$ & $\begin{array}{c}\text { ÁREA } \\
\text { URBANA } \\
\text { BARCELONA }\end{array}$ & $\begin{array}{c}\text { ÁREA } \\
\text { URBANA } \\
\text { VALENCIA }\end{array}$ & $\begin{array}{c}\text { ÁREA } \\
\text { URBANA } \\
\text { BILBAO }\end{array}$ & $\begin{array}{l}\text { ÁREA } \\
\text { URBANA } \\
\text { SEVILLA }\end{array}$ & $\begin{array}{c}\text { RESTO } \\
\text { ÁREAS } \\
\text { URBANAS }\end{array}$ & $\begin{array}{c}\text { ÁREAS } \\
\text { RURALES }\end{array}$ & TOTAL \\
\hline $\begin{array}{l}\text { Artes gráficas y } \\
\text { reproducción de } \\
\text { soportes grabados }\end{array}$ & 25,16 & 22,15 & 3,56 & 2,55 & 2,13 & 28,61 & 15,83 & 100 \\
\hline Industria editorial & 38,47 & 20,88 & 3,20 & 2,55 & 2,42 & 27,04 & 5,44 & 100 \\
\hline $\begin{array}{l}\text { Actividades de cine, } \\
\text { televisión, sonido y } \\
\text { edición musical }\end{array}$ & 34,00 & 15,57 & 3,25 & 3,52 & 6,47 & 29,89 & 7,29 & 100 \\
\hline $\begin{array}{l}\text { Actividades de } \\
\text { programación y } \\
\text { emisión de radio/ } \\
\text { televisión }\end{array}$ & 31,82 & 16,48 & 6,90 & 1,84 & 2,31 & 34,58 & 6,07 & 100 \\
\hline $\begin{array}{l}\text { Servicios técnicos } \\
\text { de arquitectura e } \\
\text { ingeniería }\end{array}$ & 28,20 & 12,95 & 3,83 & 3,87 & 4,91 & 35,51 & 10,72 & 100 \\
\hline $\begin{array}{l}\text { Publicidad y estudios } \\
\text { de mercado }\end{array}$ & 35,82 & 20,16 & 3,27 & 2,20 & 3,17 & 29,03 & 6,36 & 100 \\
\hline $\begin{array}{l}\text { Otras actividades } \\
\text { profesionales, } \\
\text { científicas y técnicas }\end{array}$ & 21,65 & 19,87 & 5,16 & 2,25 & 3,06 & 34,49 & 13,53 & 100 \\
\hline $\begin{array}{l}\text { Actividades de } \\
\text { creación, artísticas y } \\
\text { espectáculos }\end{array}$ & 22,52 & 23,19 & 3,91 & 2,17 & 4,40 & 30,82 & 12,98 & 100 \\
\hline $\begin{array}{l}\text { Bibliotecas, archivos, } \\
\text { museos y otras } \\
\text { culturales }\end{array}$ & 18,46 & 20,28 & 2,52 & 2,15 & 2,65 & 34,63 & 19,31 & 100 \\
\hline $\begin{array}{r}\text { Empleo en Economía } \\
\text { Creativa }\end{array}$ & 29,29 & 17,91 & 3,84 & 2,89 & 3,75 & 31,95 & 10,37 & 100 \\
\hline Empleo Total España & 15,66 & 12,41 & 3,58 & 2,17 & 2,81 & 37,92 & 25,45 & 100 \\
\hline
\end{tabular}

Fuente Tesorería General de la Seguridad Social y elaboración propia.

En tan solo 56 de las 851 áreas urbanas, el peso relativo de su empleo en sectores creativos respecto del total supera el correspondiente al del conjunto del país, lo que se traduce en un cociente de localización por encima de la unidad. Al mismo tiempo, si se jerarquiza a todas esas áreas urbanas en función de su volumen total de ocupación en sectores creativos, 41 de las especializadas están entre las 200 primeras, siendo muy escasas las que se sitúan por debajo de ese umbral. En otras palabras, 
la mayor parte de las ciudades sigue estando al margen de la economía creativa, que continúa siendo patrimonio de un número bastante reducido: en 623 de ellas no se alcanza el centenar de empleos en este tipo de actividades y 543 no superan un cociente de localización de 0,50 , lo que equivale a una proporción inferior al $2 \%$ de su empleo total.

FIGURA 3 | Concentración y especialización de las áreas urbanas españolas en economía creativa, 2009

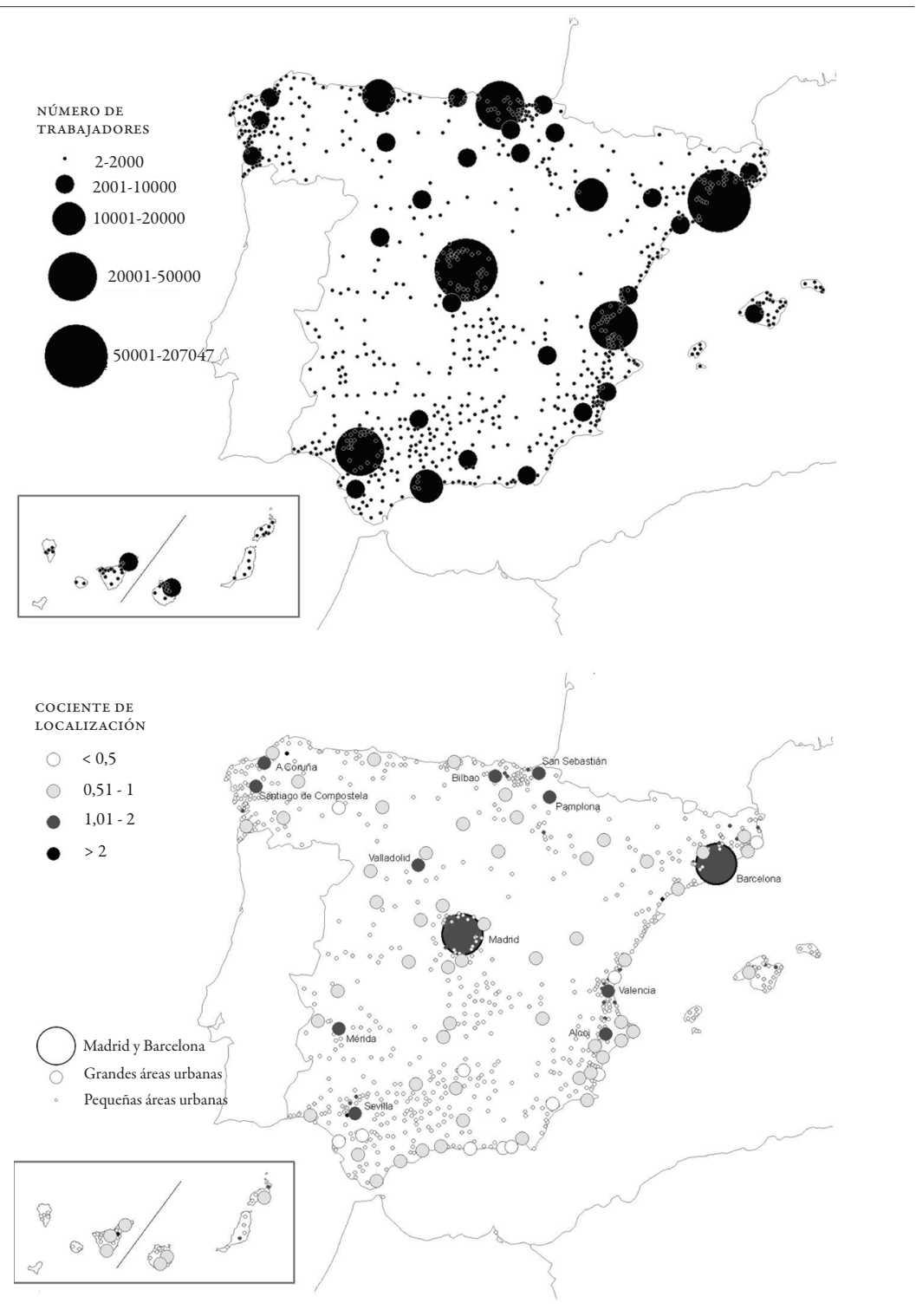

fuente Tesorería General de la Seguridad Social y elaboración propia. 
Finalmente, si se cambia la escala de análisis utilizada, en el interior de las cinco mayores áreas urbanas la resistencia al traslado de estas actividades desde su ciudad central y hacia las situadas en la periferia metropolitana resulta muy acusada (Cuadro 4), hasta el punto de que dos tercios de sus empleos $(66,48 \%)$ aún se localizan en ellas, con valores máximos en los casos de Sevilla (72,73\%) y Madrid (71,48\%), pero superando siempre la mitad del total en los de Valencia $(66,53 \%)$, Barcelona $(59,52 \%)$ y Bilbao $(50,85 \%)$. La economía creativa contribuye, por tanto, de forma bastante modesta a las tendencias difusoras hoy habituales, que favorecen la configuración de metrópolis policéntricas y de carácter difuso, moderando la importancia relativa de la metrópoli central y aumentando la densidad y complejidad de los flujos diarios dentro de la aglomeración. Se ponen así de manifiesto nuevas formas de jerarquización territorial en las que factores como las ventajas de la centralidad, la proximidad espacial o el capital simbólico asociado a determinados enclaves urbanos altamente representativos mantienen su influencia de manera selectiva y contribuyen así a configurar territorios metropolitanos más complejos y segmentados (Méndez, 2007).

CUADRO 4 | Porcentaje de empleo en actividades de economía creativa en las ciudades centrales de las mayores áreas urbanas españolas, 2009

\begin{tabular}{|c|c|c|c|c|c|c|}
\hline ACTIVIDADES & MADRID & BARCELONA & VALENCIA & SEVILLA & BILBAO & TOTAL \\
\hline $\begin{array}{l}\text { Artes gráficas y reproducción de } \\
\text { soportes grabados }\end{array}$ & 43,80 & 28,65 & 34,93 & 53,42 & 40,35 & 37,40 \\
\hline Industria editorial & 82,65 & 76,59 & 83,80 & 70,52 & 70,70 & 79,94 \\
\hline $\begin{array}{l}\text { Actividades de cine, televisión, } \\
\text { sonido y edición musical }\end{array}$ & 64,51 & 67,24 & 63,57 & 33,55 & 69,84 & 62,25 \\
\hline $\begin{array}{l}\text { Actividades de programación y } \\
\text { emisión de radio/TV }\end{array}$ & 28,11 & 34,27 & 20,69 & 80,19 & 91,31 & 32,94 \\
\hline $\begin{array}{l}\text { Servicios técnicos de arquitectura } \\
\text { e ingeniería }\end{array}$ & 75,25 & 55,06 & 71,89 & 79,74 & 37,10 & 67,81 \\
\hline Publicidad y estudios de mercado & 79,76 & 71,20 & 82,50 & 80,59 & 67,67 & 76,86 \\
\hline $\begin{array}{l}\text { Otras actividades profesionales, } \\
\text { científicas y técnicas }\end{array}$ & 73,55 & 65,08 & 69,87 & 76,71 & 51,51 & 69,18 \\
\hline $\begin{array}{l}\text { Actividades de creación, artísticas y } \\
\text { espectáculos }\end{array}$ & 80,05 & 69,51 & 77,54 & 78,41 & 65,05 & 74,82 \\
\hline $\begin{array}{l}\text { Bibliotecas, archivos, museos y otras } \\
\text { actividades culturales }\end{array}$ & 83,42 & 77,98 & 77,39 & 88,78 & 61,94 & 80,00 \\
\hline Economía Creativa & 71,48 & 59,52 & 66,53 & 72,73 & 50,85 & 66,48 \\
\hline
\end{tabular}

fuente Tesorería General de la Seguridad Social y elaboración propia. 
No obstante lo anterior, el predominio que ejercen las mayores metrópolis y el atractivo de las grandes cifras aportan una perspectiva que, aunque cierta, resulta insuficiente. Se hace así necesario ampliar ese diagnóstico para incorporar otras lógicas espaciales complementarias, menos evidentes pero que permiten dar cuenta de la diversidad interna que se oculta bajo la genérica alusión a la economía creativa. En ese sentido, puede destacarse la importancia de algunas ciudades de tamaño medio cuyos actores han sido capaces de poner en valor determinados recursos específicos para generar ventajas competitivas, junto con la evidencia de trayectorias locales específicas que se reflejan en tipos de especialización muy heterogéneos en áreas urbanas del mismo rango. Y finalizar con un apunte sobre las diversas lógicas que se superponen en el interior de las principales aglomeraciones metropolitanas por corresponder a actividades con estructuras, dinámicas y efectos contrastados sobre el territorio.

\section{Más allá de la aglomeración: otras tendencias en la organización espacial de la economía creativa}

En términos generales, parece fuera de toda duda la existencia de una asociación espacial de sentido positivo entre el tamaño urbano y la importancia relativa del empleo en economía creativa. Pero cuando la atención se centra en lugares concretos, esa relación muestra diferencias significativas que hacen pensar en la influencia ejercida por factores locales imposibles de identificar con precisión a la escala y con la información aquí utilizadas, pero que apuntan a líneas de investigación posibles de profundizar. De este modo, si se consideran las cuarenta áreas urbanas con mayor volumen de empleo en sectores creativos al finalizar 2009 (Cuadro 5), lo primero que destaca es que tan solo once de ellas muestran cocientes de localización superiores a la unidad, pues los altos niveles de especialización de Madrid $(\mathrm{CL}=1,87)$ y Barcelona $(\mathrm{CL}=1,44)$ sesgan los valores estadísticos resultantes. Junto con las cinco mayores aglomeraciones, todas ellas especializadas en este tipo de actividades, es al descender en la jerarquía cuando se aprecia que áreas urbanas de segundo nivel, como las de A Coruña, Valladolid, San Sebastián o Pamplona, destacan por encima de otras de tamaño similar (Murcia, Palma de Mallorca, Vigo, Alicante...) o incluso superior (Málaga, Zaragoza, Área Central Asturiana).

Todas las áreas urbanas mencionadas muestran una significativa presencia tanto de las industrias y servicios culturales como de aquellos otros calificados de creativos, pero son evidentes ciertas señas de identidad. Aunque en todos los casos los servicios de publicidad y arquitectura son los que generan mayor volumen de empleo, que llega al 63\% del total en Valladolid, en los casos de A Coruña y Pamplona destaca el peso relativo del sector editorial y de artes gráficas (20\% y $24 \%$, respectivamente, de su empleo creativo), mientras San Sebastián muestra mayor diversificación, por la destacada presencia de actividades culturales, de diseño y audiovisuales (33\% del empleo creativo), reflejo de ciertas herencias de la etapa industrial y de políticas urbanas activas en la promoción de nuevos sectores ahora valorados como estratégicos. 
Por debajo de ese rango urbano, apenas unas pocas ciudades patrimoniales, como Santiago de Compostela o Mérida, muestran una especialización nítida, si bien ese capital cultural heredado no resulta suficiente por sí solo para promover una significativa proporción del empleo local. Esa distinta respuesta puede apreciarse en casos como los de Granada, Córdoba, Girona, León, Toledo, Salamanca o Burgos, con cocientes netamente inferiores a la unidad, bien por la insuficiente puesta en valor de tales recursos o por el mayor dinamismo relativo de otro tipo de actividades.

CUADRO 5 | Especialización en economía creativa de las principales áreas urbanas, 2009

\begin{tabular}{|c|c|c|c|c|c|}
\hline \multicolumn{3}{|c|}{ Cocientes Localización (CL) superiores a 1} & \multicolumn{3}{|c|}{ Cocientes Localización (CL) inferiores a 0,90 } \\
\hline RANGO & ÁREA URBANA & $\mathrm{CL}$ & RANGO & ÁREA URBANA & $\mathrm{CL}$ \\
\hline 1 & Madrid & 1,87 & 8 & $\begin{array}{l}\text { Área Central de } \\
\text { Asturias }\end{array}$ & 0,85 \\
\hline 2 & Barcelona & 1,44 & 11 & Murcia & 0,88 \\
\hline 3 & Valencia & 1,07 & 13 & Palma de Mallorca & 0,89 \\
\hline 4 & Sevilla & 1,33 & 14 & Vigo & 0,79 \\
\hline 5 & Bilbao & 1,33 & 15 & Alicante & 0,89 \\
\hline 9 & A Coruña & 1,22 & 17 & $\begin{array}{l}\text { Las Palmas Gran } \\
\text { Canaria }\end{array}$ & 0,83 \\
\hline 10 & Valladolid & 1,36 & 19 & Granada & 0,82 \\
\hline 12 & San Sebastián & 1,17 & 20 & Bahía de Cádiz & 0,76 \\
\hline 16 & Pamplona & 1,06 & 22 & Tarragona & 0,83 \\
\hline 23 & $\begin{array}{l}\text { Santiago de } \\
\text { Compostela }\end{array}$ & 1,83 & 25 & Córdoba & 0,86 \\
\hline \multirow[t]{5}{*}{37} & Mérida & 1,17 & 26 & Girona & 0,88 \\
\hline & & & 27 & Castellón & 0,81 \\
\hline & & & 29 & Lleida & 0,89 \\
\hline & & & 30 & León & 0,82 \\
\hline & & & 31 & Almería & 0,72 \\
\hline \multicolumn{3}{|c|}{ Cocientes Localización (CL) entre 0,90-1 } & 32 & Toledo & 0,87 \\
\hline Rango & Área Urbana & CL & 33 & Salamanca & 0,78 \\
\hline 6 & Málaga & 0,99 & 34 & Burgos & 0,70 \\
\hline 7 & Zaragoza & 0,97 & 35 & Albacete & 0,73 \\
\hline 18 & $\begin{array}{l}\text { Santa Cruz-La } \\
\text { Laguna }\end{array}$ & 0,9 & 36 & Badajoz & 0,79 \\
\hline 21 & Santander & 0,96 & 38 & Jaén & 0,63 \\
\hline 24 & Vitoria-Gasteiz & 0,93 & 39 & Huelva & 0,80 \\
\hline 28 & Logroño & 1 & 40 & Guadalajara & 0,69 \\
\hline
\end{tabular}

Fuente Tesorería General de la Seguridad Social y elaboración propia. 
Esta nueva complejidad territorial es una de las facetas más importantes del impacto sobre el desarrollo urbano de la economía creativa, más visible aún al aproximar la observación a escala intrametropolitana. Mediante el análisis de los datos de empleo en el interior de las áreas de Madrid y Barcelona (Figura 4), es posible identificar las tendencias dominantes de distribución espacial de la economía creativa en relación con los tres supuestos que se planteaban en páginas anteriores: fuerte tendencia a la concentración, propensión a la formación de clusters localizados e importancia de las inercias espaciales vinculadas a las herencias y estrategias propias de cada ciudad. Se confirma así un alto grado de polarización común a ambos casos, si bien al mismo tiempo pueden apreciarse diferencias no menos significativas.

En el área de Barcelona se constata la existencia de un sistema urbano policéntrico más desarrollado, donde no solo las ciudades más próximas a la capital concentran un volumen importante de empleos, sino que es fácilmente identificable la presencia de capitales comarcales externas al área urbana oficial, aunque bien conectadas por vías de alta capacidad, que operan como subcentros de ámbitos funcionales de segundo orden (Vic, Berga, Manresa, Igualada...), situación que en Madrid no es posible detectar. En el interior del área urbana madrileña sí se identifican algunas ciudades del cuadrante noroeste que muestran altos niveles de concentración (Alcobendas, San Sebastián de los Reyes, Tres Cantos, Pozuelo de Alarcón y Las Rozas), pero su número es más reducido. Por contra, en Barcelona no se observan grandes concentraciones ajenas a la ciudad central, pero es más densa la constelación de ciudades medias, sobre todo en el Vallés (San Cugat, Cerdanyola, Terrassa, Sabadell...), y el Baix Llobregat (Hospitalet, Sant Joan Despí...). Estos diferentes grados de concentración pueden precisarse con mayor exactitud si se desagregan las actividades que conforman la economía creativa y se centra la atención en aquellas que muestran un comportamiento espacial singular al comparar ambas aglomeraciones urbanas.

En este sentido, Madrid y Barcelona comparten una localización mayoritaria de los centros de trabajo de artes gráficas en la periferia metropolitana (Cuadro 4), con valores muy superiores en el caso de Barcelona (solo 28,65\% en la capital frente al resto) respecto de Madrid (43,80\%). La naturaleza eminentemente industrial de esta actividad, intensiva en mano de obra y de bajo valor añadido, explica la búsqueda de espacios periféricos con una oferta inmobiliaria más adaptada a sus necesidades productivas y un precio inferior, pero localizadas en las inmediaciones de grandes ciudades para garantizar las ventajas de la aglomeración en una actividad orientada a satisfacer las demandas de un mercado mayoritariamente local. En ambos casos el análisis constata su propensión a formar concentraciones espaciales de empresas en las ciudades más importantes del Sur Metropolitano y el Corredor del Henares de Madrid, o en la comarca del Baix Llobregat y el Vallés en Barcelona, lo que en principio parece asociarse a las dinámicas de proximidad, si bien sería necesario el uso de técnicas complementarias de análisis para poder confirmar este extremo.

Esta misma tendencia hacia la búsqueda de espacios periféricos se constata en el caso de las actividades vinculadas con la programación de radio y televisión. En 
ambos casos la ciudad central alberga tan solo un tercio de estos empleos, lo que evidencia ciertas pautas de localización que evitan la lógica de la concentración, aunque se mantiene un alto grado de selectividad espacial, pues son muy pocas las ciudades próximas con una presencia significativa de empleos en este tipo de actividades (Sant Joan Despí y Sant Cugat del Vallés en Barcelona, Pozuelo de Alarcón y San Sebastián de los Reyes en Madrid). En ambos casos, la presencia de las respectivas televisiones autonómicas (Telemadrid en Pozuelo y TV3 en Sant Joan Despí) y de algunas cadenas privadas de ámbito nacional (Antena3 en San Sebastián de los Reyes y laSexta en Pozuelo), además de importantes instalaciones de RTVE (Pozuelo, Sant Cugat), explican este alto grado de concentración, a veces favorecido por la promoción de espacios para tales actividades (Ciudad de la Imagen, en Pozuelo de Alarcón).

En el otro extremo, la industria editorial muestra una enorme resistencia a situarse fuera de la ciudad central. Se trata de una actividad de larga tradición urbana, muy relacionada con el valor simbólico de ciertos enclaves centrales presentes en las grandes ciudades y necesitadas de las ventajas que aportan las economías de urbanización, así como de las dinámicas de proximidad orientadas al fortalecimiento del capital social de este colectivo, si bien los datos disponibles no permiten precisar el grado de cooperación entre las empresas editoriales presentes en ambas ciudades.

La actividad asociada a bibliotecas, archivos, museos, también presenta en ambas aglomeraciones urbanas una clara tendencia a la concentración en la ciudad central. En este caso, aunque se trata de una actividad relacionada con una lógica de provisión equitativa de un equipamiento público, lo que implicaría una distribución espacial menos concentrada, pesa más el hecho de que ambas ciudades centrales atesoran un rico patrimonio y grandes instituciones culturales públicas y privadas, lo que necesariamente opera como factor determinante para explicar ese alto grado de polarización.

En cuanto a actividades con comportamientos diferentes en ambas áreas, destaca la proporción mucho mayor (20 puntos porcentuales) de empleos en el sector de servicios técnicos de arquitectura e ingeniería de la ciudad de Madrid respecto a la de Barcelona, que se reduce a menos de la mitad en el caso de los de publicidad y estudios de mercado. Para Madrid, los municipios de Tres Cantos y Pozuelo de Alarcón son los que presentan un volumen de empleo más elevado, lo que permite constatar una vez más la contraposición de funciones entre noroeste y sureste de la aglomeración. En el caso de la capital catalana, este tipo de actividades refleja mayor dispersión, fundamentalmente por el sector suroeste de la aglomeración (Cornellá, Hospitalet, Esplugues y El Prat) y en las ciudades más importantes de la comarca del Vallés (Sant Cugat, Cerdanyola, Tarrasa y Sabadell), como muestra de un sistema urbano más maduro.

En resumen, la localización del empleo en actividades vinculadas con la economía creativa puede considerarse como un indicador significativo para identificar subcentros funcionales en el lento y aún limitado avance hacia un sistema urbano policéntrico, que mantiene contrastes intrametropolitanos importantes desde un punto de vista cualitativo. Sin embargo, no todas las actividades clasificadas como 
creativas muestran las mismas lógicas de organización espacial, reflejo de la complejidad que conlleva la superposición de múltiples factores de localización junto con la singularidad de cada espacio urbano, resultado de trayectorias locales específicas.

FIGURA 4 | Número total de afiliados en economía creativa en Madrid y Barcelona, 2009

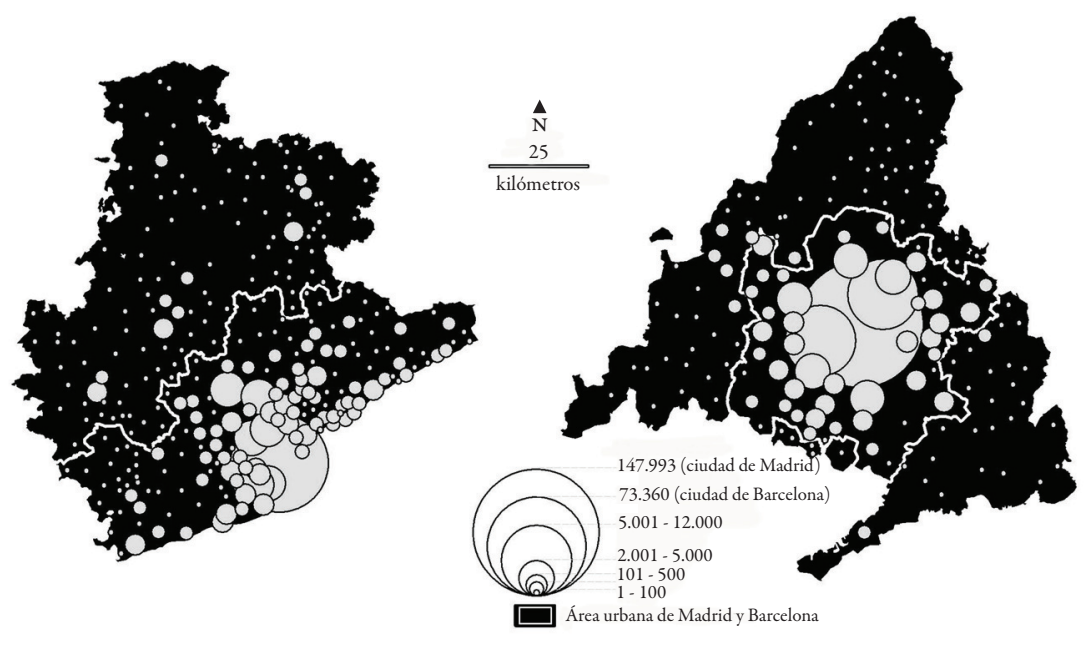

Fuente Tesorería General de la Seguridad Social y elaboración propia.

\section{Conclusiones}

A lo largo de la última década, la economía creativa ha recibido una creciente atención desde el punto de vista del desarrollo urbano. Es evidente que, al tratarse de actividades intensivas en conocimiento, con una demanda global creciente y un riesgo relativamente bajo de deslocalización empresarial, presentan gran interés para los gobiernos europeos, que ven en ellas un factor clave para la regeneración y el desarrollo sostenido de las economías urbanas. Sin embargo, es también cierto que persisten ciertas controversias sobre aspectos fundamentales de carácter conceptual, que dejan lugar para un amplio debate académico. Con base en el análisis de los sectores creativos en el sistema urbano español y, a partir de ahí, en sus dos principales áreas metropolitanas, el trabajo realizado ha permitido obtener resultados que apuntan a precisar algunos lugares comunes desde el punto de vista teórico y matizar afirmaciones anteriores, superando también la mera referencia a la concentración espacial de estas actividades.

En primer lugar, las estadísticas europeas sobre economía creativa ponen de manifiesto que estas actividades alcanzan en la actualidad una importancia creciente en la definición de la nueva jerarquía metropolitana, y sitúan a Madrid y Barcelona entre las áreas más destacadas desde este punto de vista. No obstante, al descender 
en la jerarquía se constata que estamos en presencia de actividades que representan muy poco en la gran mayoría de las áreas urbanas españolas, por lo que el significado de esta línea de investigación mantiene su sentido en determinados ámbitos, pero su traslación a otros parece más discutible.

La frecuente tentación de adoptar de forma acrítica determinados modelos, estrategias o recetas de desarrollo surgidos en otros contextos exige, pues, mantener en este caso una perspectiva crítica en relación con el papel de las industrias y servicios creativos como factor de desarrollo urbano. Es innegable que existen evidencias sobre su importancia y significado en los estratos superiores del sistema urbano y en ciudades que han puesto en valor sus recursos culturales heredados o han sido capaces de generar otros. Pero tampoco puede ignorarse que parte del auge actual de esta temática en la bibliografía reciente se corresponde con la construcción de una narrativa de la creatividad que, tal como se señaló, fue promovida por el gobierno británico hace más de una década y ha recibido luego un fuerte impulso por parte de instituciones internacionales, en especial europeas, en el marco de la pretendida construcción de un nuevo modelo de desarrollo coherente con la llamada sociedad del conocimiento.

En segundo lugar, respecto del comportamiento de estas actividades a escala intrametropolitana, la investigación realizada permite observar su resistencia al traslado desde la ciudad central, contribuyendo muy modestamente a la configuración de estructuras territoriales policéntricas. En tal sentido, el análisis comparativo de Madrid y Barcelona corrobora los resultados de estudios anteriores en relación con que la configuración y evolución de las actividades creativas resultan fuertemente dependientes del contexto y la evolución de cada ciudad. En efecto, en ambos casos la localización de clusters empresariales especializados guarda estrecha relación con sus propias singularidades, como las características de sus sistemas urbanos o las trayectorias locales de determinadas ciudades ubicadas en su interior.

Uno de los aspectos más novedosos del estudio realizado es el análisis de estas actividades para el conjunto formado por las 851 áreas urbanas españolas, que permitió medir no solo su alta selectividad espacial, sino también la importancia de algunas ciudades de tamaño medio, descuidadas por lo general en los estudios sobre economía creativa y desarrollo urbano. Los datos confirman que, en un contexto en que la mayor parte de esas áreas sigue quedando al margen, algunas consiguen insertarse competitivamente, bien por contar con un importante patrimonio cultural como, sobre todo, por haber aplicado políticas de promoción de determinados clusters. Esto introduce la influencia de factores locales (trayectoria histórica, instituciones, coaliciones locales de actores, etcétera) no abordados en esta panorámica general, que exigirán métodos de investigación diferentes para lograr una verdadera comprensión de su significado y plantear propuestas de políticas públicas más acordes con el contexto específico de cada ciudad. IEURE 


\section{Bibliografía}

Bathelt, H., Malmberg, A. \& Maskell, P. (2004). Clusters and knowledge: Local buzz, global pipelines and the process of knowledge creation. Progress in Human Geography, 28(1), 31-56.

Boix, R. \& Galetto, V. (2006). Mapping Marshallian industrial districts in Spain. Comunicación presentada a la European Network on Industrial Policy (EUNIP) International Conference, 2006. Universidad de Limerick.

Boix, R., Lazzeretti, L., Capone, F., De Propris, L., \& Sánchez, D. (2010). The geography of creative industries in Europe: Comparing France, Great Britain, Italy and Spain. En 50th European Congress of the European Regional Science Association International, "Sustainable Regional Growth and Development in the Creative Knowledge Economy", 23 August, Jonkoping, Sweden. Disponible en http://www.uv.es/raboixdo/references/2010/10007.pdf

Capone, F. (2008). Mapping and analysing creative systems in Italy (1991-2001). En P. Cooke \& L. Lazzeretti (Eds.), Creative cities, cultural cluster and local economic development (pp. 338364). Cheltenham: Edward Elgar.

Comisión Europea (2010). Libro Verde. Liberar el potencial de las industrias culturales y creativas. Bruselas: Autor.

Cooke, P. \& Lazzeretti, L. (Eds.). (2008). Creative cities, cultural clusters and local economic development. Cheltenham: Edward Elgar.

Cunningham, S. (2002). From cultural to creative industries. Theory, industry, and policy implications. Quarterly Journal of Media Research and Resources, 102, 54-65.

Currid, E. \& Williams, S. (2006). Two cities, five industries: Similarities and differences within and between cultural industries in New York and Los Angeles. Working Paper. Disponible en http:// www.learcenter.org/pdf/CurridWilliams2Cities5Indust.pdf

Department for Culture, Media and Sport (DCMS). (1998). Creative industries mapping document. Londres: Autor.

De Propris, L., Chapain, C., Cooke, P., MacNeill, S., \& Mateos-García, J. (2009). The geography of creativity. Londres: National Endowment for Science, Technology and the Arts (NESTA).

Fernández, V. R. \& Brandão, C. (Dirs.). (2010). Escalas y politicas de desarrollo regional. Desafíos para América Latina. Buenos Aires: Miño y Dávila.

Florida, R. (2002). The rise of the creative class and how it's transforming work, leisure, community and everyday life. Nueva York: Basic Books.

Florida, R. (2005). Cities and the creative class. Londres: Routledge.

Florida, R.; Mellander, C. \& Stolarick, K. (2008). Inside the black box of regional development. Human capital, the creative class and tolerance. Journal of Economic Geography, 8(5), 615-649.

Galloway, S. (2008). Industries culturelles ou industries créatives: approche critique. III Journées d'Économie de la Culture. Disponible en http://jec.culture.fr

Garnham, N. (2005). From cultural to creative industries. International Journal of Cultural Policy, $11(1), 15-29$.

Gertler, M., Florida, R., Gates, G., \& Vinodrai, T. (2002). Competing on creativity: Placing Ontario's cities in North American context. Toronto: Munk Centre for International Studies, University of Toronto. Disponible en http://www.investinginchildren.on.ca/Communications/ articles/Competing\%20on\%20Creativity.pdf 
Glaeser, E. L. (2004). Richard Florida's The rise of the creative class. [Reseña del libro]. Disponible en http://www.economics.harvard.edu/faculty/glaeser/files/Review_Florida.pdf

Hall, P. (2004). Creativity, culture, knowledge and the city. Built Environment, 30(3), 256-258.

Higgs, P., Cunningham, S. \& Bakhshi, H. (2008). Beyond the creative industries: Mapping the creative economy in the UK. Londres: National Endowment for Science, Technology and the Arts (NESTA).

KEA European Affairs. (2006, Oct.). The economy of culture in Europe. [Estudio preparado para la Comisión Europea]. Bruselas: KEA European Affairs. Disponible en http://www.keanet. eu/ecoculture/studynew.pdf

Kovács, Z, Murie, A., Musterd, S., Gritsai, O., \& Pethe, H. (2007). Comparing paths of creative knowledge regions. ACRE Report 3. Amsterdam: Amsterdam Institute for Metropolitan and International Development Studies (AMIDSt), University of Amsterdam. Disponible en http://acre.socsci.uva.nl/results/index.html

Lazzeretti, L. (2006). Creative firms in creative regions: The case of Florence. En P. Cooke \& D. Schwarz (Eds.), Creative regions: Technology, culture and knowledge entrepreneurship (pp. 169-196). Cheltenham: Edward Elgar.

Lazzeretti, L., Boix, R. \& Capone, F. (2008). Do creative industries cluster? Mapping creative local production systems in Italy and Spain. Industry \& Innovation, 15(5), 549-567.

Manito, F. (Ed.). (2010). Ciudades creativas. Vol. 2: Creatividad, innovación, cultura y agenda local. Barcelona: Bellaterra Ediciones.

Martin, R. \& Sunley, P. (2003). Deconstructing clusters: Chaotic concept or policy panacea? Journal of Economic Geography, 3(1), 5-36.

Méndez, R. (2007). El territorio de las nuevas economías metropolitanas. EURE, 33(100), 51-67. doi: 10.4067/S0250-71612007000300004

Méndez, R. \& Sánchez Moral, S. (2011). Spanish cities in the knowledge economy: theoretical debates and empirical evidences. European Urban and Regional Studies, 18(2), 136-155. doi: $10.1177 / 0969776410381039$

Ministerio de Fomento (2006). Atlas estadístico de las áreas urbanas de España, 2006. Madrid: Ministerio de Fomento. Disponible en http://siu.vivienda.es/portal/

Mommaas, H. (2004). Cultural clusters and the post-industrial city: Towards the remapping of urban cultural policy. Urban Studies, 41(3), 507-532.

Musterd, S., Bontje, M., Chapain, C., Kovacs, Z. \& Murie, A. (2007). Accomodating creative knowledge. A literature review from a European perspective. ACRE Report 1. Amsterdam: Amsterdam Institute for Metropolitan and International Development Studies (AMIDSt), Universidad de Amsterdam. Disponible en http://acre.socsci.uva.nl/results/reports.html

Musterd, S. \& Murie, A. (2010). Making competitive cities. Pathways, actors and policies. Londres: Blackwell.

O'Connor, J. (2008). The cultural and creative industries: A review of the literature. A report for creative partnerships. Londres: Arts Council of England.

Pareja-Eastaway, M. (2009). ¿Factores soft o hard? Determinantes para la localización de empresas creativas y del conocimiento en la Región Metropolitana de Barcelona. En F. Manito (Ed.), Ciudades creativas. Vol. 1: Cultura, territorio, economia y ciudad (pp. 23-27). Barcelona: Fundación Kreanta. 
Peck, J. (2005). Struggling with the creative class. International Journal of Urban and Regional Research, 29(4), 740-770.

Pesquera, M., Casares, P., Coto Millán, P. \& Inglada, V. (2010). Innovación empresarial, clase creativa y crecimiento económico en España. Valencia: Tirant lo Blanch.

Pierson, P. (2000). Increasing returns, path dependence, and the study of politics. The American Polit ical Science Review, 94(2), 251-267.

Power, D. \& Nielsen, T. (2010). Priority sector report: Creative and cultural industries. Europe INNOVA, European Cluster Observatory. Disponible en http://creativebusiness.org/images /CreativeAndCulturalIndustries.pdf

Santagata, W. (2005). Cultural districts, clusters and economic development. En V. Ginsburgh y D. Throsby (Eds.), Handbook on the economics of art and culture (pp. 1101-1119). Amsterdam: Elsevier.

Scott, A. J. (2006). Creative cities: Conceptual issues and policy questions. Journal of Urban Affairs, 28(1), 1-17. doi/abs/10.1111/j.0735-2166.2006.00256.x

Scott, A. J. (2009). Human capital resources and requirements across the metropolitan hierarchy of the USA. Journal of Economic Geography, 9, 207-226.

Scott, A. J. \& Leriche, F. (2005). Les ressorts géographiques de l'économie culturelle: du local au mondial. L’Espace Géographique, 34(3), 207-222. Disponible en http://www.cairn.info /revue-espace-geographique-2005-3-page-207.htm

Shearmur, R. (2006). L'aristocratie mobile du savoir et son tapis rouge. Quelques réflexions sur les thèses de Richard Florida. En D.-G. Tremblay \& R. Tremblay (Eds.), La compétitivité urbaine à l'ère de la nouvelle économie. Enjeux et défis (pp. 285-303). Montreal: Presses Universitaires du Québec.

Simmie, J., Carpenter, J., Chadwick, A., \& Martin, R. (2008). History matters: Path dependence and innovation in British city-regions. Londres: National Endowment for Science, Technology and the Arts (NESTA).

Stehr, N. (2002). Knowledge and economic conduct. The social foundations of the modern economy. Toronto: University of Toronto Press.

Stolarick, K. \& Florida, R. (2006). Creativity, connections and innovation: A study of linkages in the Montréal region. Environment and Planning A, 38(10), 1799-1817.

Storper, M. \& Venables, A. J. (2004). Buzz: Face-to-face contact and the urban economy. Journal of Economic Geography, 4(4), 351-370. Disponible en http://eprints.lse.ac.uk/20008/1/ Buzz_Face-to-Face_Contact_and_the_Urban_Economy.pdf

Throsby, D. (2008). From cultural to creative industries: The specific characteristics of the creative industries. III Journées d'Économie de la Culture. Disponible en http://jec.culture.fr

Törnqvist, G. (1983). Creativity and the renewal of regional life. En A. Buttimer (Ed.), Creativity and context: A seminar report (pp. 91-112). Lund: Gleerup.

Unctad [Conferencia de las Naciones Unidas sobre Comercio y Desarrollo]. (2008). Creative Economy Report. Ginebra-Nueva York: Autor.

Unctad [Conferencia de las Naciones Unidas sobre Comercio y Desarrollo]. (2010). Creative Economy Report. Ginebra-Nueva York: Autor.

Unesco [Organización de las Naciones Unidas para la Educación, la Ciencia y la Cultura]. (2006). Understanding creative industries: Cultural statistics for public-policy making. París: Autor. 
Vale, M. (2011). Innovation networks and local and regional development policy. En A. Pike, A. Rodríguez-Pose \& J. Tomaney (Eds.), Handbook of local and regional development (pp. 413-424). Nueva York: Routledge.

Wu, W. (2005). Dynamic cities and creative clusters. World Bank Policy Research Working Paper 3509. Disponible en http://ideas.repec.org/p/wbk/wbrwps/3509.html 